\title{
Experimental Study on Detection of Deterioration in Concrete Using Infrared Thermography Technique
}

\author{
Jungwon Huh, ${ }^{1}$ Quang Huy Tran, ${ }^{1}$ Jong-Han Lee, ${ }^{2}$ DongYeob Han, ${ }^{1}$ \\ Jin-Hee Ahn, ${ }^{3}$ and Solomon Yim ${ }^{4}$ \\ ${ }^{1}$ Department of Ocean Civil Engineering, Chonnam National University, Yeosu 59626, Republic of Korea \\ ${ }^{2}$ Department of Civil Engineering, Daegu University, Gyeongsan, Gyeongbuk 38453, Republic of Korea \\ ${ }^{3}$ Department of Civil Engineering, Gyeongnam National University of Science and Technology, Jinju, \\ Gyeongnam 52725, Republic of Korea \\ ${ }^{4}$ Department of Civil \& Construction Engineering, Oregon State University, Corvallis, OR 97331, USA
}

Correspondence should be addressed to Jong-Han Lee; jonghan@daegu.ac.kr

Received 4 March 2016; Accepted 30 March 2016

Academic Editor: Velu Saraswathy

Copyright (C) 2016 Jungwon Huh et al. This is an open access article distributed under the Creative Commons Attribution License, which permits unrestricted use, distribution, and reproduction in any medium, provided the original work is properly cited.

Concrete is certainly prone to internal deteriorations or defects during the construction and operating periods. Compared with other nondestructive techniques, infrared thermography can easily detect the subsurface delamination in a very short period of time, but accurately identifying its size and depth in concrete is a very challenging task. In this study, experimental testing was carried out on a concrete specimen having internal delaminations of various sizes and at varying depths. Delaminations at 1 and $2 \mathrm{~cm}$ deep showed a good temperature contrast after only 5-minute heating, but delaminations at $3 \mathrm{~cm}$ practically identified the value of the temperature contrast from heating of 15 minutes. In addition, the size of the delamination at $3 \mathrm{~cm}$ deep could be estimated with a difference of $10 \%$ to $28 \%$ for 20 minutes of heating. The depth of the delamination was linearly correlated with the increase in its size.

\section{Introduction}

Concrete deteriorates during the operating period with cracks and delamination due to various factors, such as repeated loading, weather and environmental conditions, wind loading, and water flow. Furthermore, delamination and air voids in concrete certainly exist during the process of construction. In particular, a lack of compaction generates these defects in some parts of a structure, that is, at the corner of the flange and web of a girder or at the connection of a wall and a column, as well as the areas with a high density of steel reinforcement or grouted ducts of posttensioning, as shown in Figure 1. Additionally, since the water entailed in the formation of concrete expands during freezing, the increase in its pressure accelerates the delamination and air voids already developed in concrete.

Currently, several nondestructive techniques (NDT), such as impact echo, coin tapping [1], ultrasonic pulse echo [2], ultrasonic surface waves [3], ground penetrating radar
(GPR) [4], and infrared (IR) thermography [5], can be applied to detect the size and depth of the defects in concrete. Compared with IR thermography, other NDT techniques are cost-ineffective and require much time and significant data interpretation $[2,6]$. One of the most significant advantages of the IR technique is the shortest detection time among alternatives, as well as its capability for evaluating an area of subsurface delamination around 3 inches $(7.62 \mathrm{~cm})$ in depth [4, 6-8]. However, quantifying the depth of delamination appears to be a big challenge, and only a few researchers have attempted to evaluate the depth of delamination using the IR technique. Cielo et al. [9] and Maldague [5] observed the change in surface temperature and the observation time of delaminated layers to estimate the depth of delamination. Later, Vaghefi in 2013 [8] confirmed the technique proposed by Maldague [5] using four concrete slabs with delaminations placed at various depths. Thus, in this study, an extensive experimental investigation and analysis into the size and depth of subsurface delamination was carried out using a long 

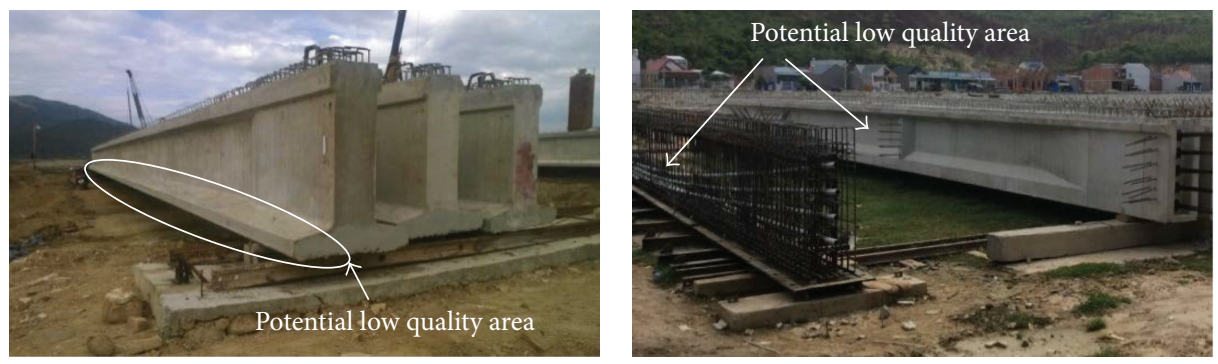

FIGURE 1: Examples of low quality areas seen during the process of construction.

wave length IR thermography technique with various heating and cooling time cycles.

\section{Fundamentals of IR Thermography}

IR light is an electromagnetic spectrum with a wavelength of 0.8 to $1000 \mu \mathrm{m}$ [10]. However, the IR thermograph technique uses only a small range of the IR spectrum from 0.8 to $14 \mu \mathrm{m}$ because the atmosphere blocks most of the spectrum. This narrow region includes near-infrared (NIR) wavelengths from 0.8 to $1.7 \mu \mathrm{m}$, short wavelength IR (SWIR) from 1 to $2.5 \mu \mathrm{m}$, middle wavelength IR (MWIR) from 2 to $5 \mu \mathrm{m}$, and long wavelength IR (LWIR) from 8 to $14 \mu \mathrm{m}$. The MWIR and LWIR bands, which show low absorption in air particles, are suitable for current camera sensor and thus are the most commonly used for IR thermography $[10,11]$.

For structural inspection purpose, the IR thermography technique is based on measuring the radiant temperature of the structure's surface. The IR thermal camera measures the IR radiation emitted from the surface of the structure and converts the detected energy into temperature values. The total radiation energy $\left(W_{\text {tot }}\right)$ received by the camera is the sum of the emission from the target object $\left(W_{\text {obj }}\right)$, the ambient source $\left(W_{\text {refl }}\right)$, and the atmosphere $\left(W_{\text {atm }}\right)[10,12,13]$, in terms of the object temperature $\left(T_{\mathrm{obj}}\right)$, the reflected temperature $\left(T_{\text {refl }}\right)$, and the atmospheric temperature $\left(T_{\text {atm }}\right)$, respectively, as follows:

$$
\begin{aligned}
W_{\text {tot }}= & W_{\text {obj }}+W_{\text {refl }}+W_{\text {atm }} \\
= & \varepsilon \cdot \tau \cdot \sigma \cdot T_{\mathrm{obj}}^{4}+(1-\varepsilon) \cdot \tau \cdot \sigma \cdot T_{\text {refl }}^{4}+(1-\tau) \cdot \sigma \\
& \cdot T_{\mathrm{atm}}^{4},
\end{aligned}
$$

where $\varepsilon$ is the object emissivity, $\tau$ is the atmospheric transmission, and $\sigma$ is the Stefan-Boltzmann constant $(=5.67 \times$ $\left.10^{-8} \mathrm{~W} / \mathrm{m}^{2} \mathrm{~K}^{4}\right)$. Thus, the temperature of the object can be calculated by

$$
\begin{aligned}
& T_{\text {obj }} \\
& \quad=\left[\frac{W_{\mathrm{tot}}-(1-\varepsilon) \cdot \tau \cdot \sigma \cdot T_{\mathrm{refl}}^{4}-(1-\tau) \cdot \sigma \cdot T_{\mathrm{atm}}^{4}}{\varepsilon \cdot \tau \cdot \sigma}\right]^{1 / 4} .
\end{aligned}
$$

When detecting defects in a structure using an IR thermal camera, the subsurface delaminations or voids in concrete exhibit a higher temperature than nearby sound areas because they interrupt the heat transfer through the concrete [8]. The high temperature in the defective area can only be detected when both the heat source and IR camera are placed on the same face of the specimen. If the heat source is placed on the opposite face, the temperature of the defective area is lower than the surrounding sound surface of concrete, with a relatively small difference between them. Figure 2 shows an example of the images observed from an IR camera placed on the same and opposite faces as the heat source. In the opposite heating configuration, the temperature of the sound concrete is higher than that of the defective area (Sp2 $>\mathrm{Sp} 1)$, as shown in Figure 2(a). In contrast, when the heat source is on the same face with the IR camera, the temperature at the defects is higher than the nearby sound areas $(\mathrm{Sp} 2<\mathrm{Sp} 1)$, as shown in Figure 2(b). Therefore, the same position for the camera and the heat source is more practical and useful, since the temperature difference between the defective and the surrounding sound areas on the surface of a concrete structure can be more easily evaluated. Thus, in this study, the size and depth of the defects in concrete were evaluated using an IR camera placed on the same face as the heat source, with variations in the times of the heating and cooling processes.

\section{Experimental Design and Procedure}

3.1. Preparation of Concrete Specimen. A concrete specimen was manufactured to include embedded delaminations of various sizes and at varying depths. The outside dimensions of the concrete specimen were $75 \times 70 \times 12 \mathrm{~cm}$ (length $\times$ width $\times$ depth), as shown in Figure 3 . The delaminations considered in this study were twelve rectangular shapes, denoted as a capital letter " $D$ " with sizes of $10 \times 10 \mathrm{~cm}, 7 \times 7 \mathrm{~cm}, 5 \times 5 \mathrm{~cm}$, and $3 \times 3 \mathrm{~cm}$ at $1 \mathrm{~cm}$ deep (D12 to D9), $2 \mathrm{~cm}$ deep (D8 to D5), and $3 \mathrm{~cm}$ deep (D4 to D1) from the specimen's surface, along with two curved shapes, denoted as a capital letter "S" as shown in Figure 3. The delaminations were simulated using polystyrene, with a thermal conductivity of $0.027 \mathrm{~W} / \mathrm{m}^{\circ} \mathrm{C}$ which is very similar to that of air, $0.024 \mathrm{~W} / \mathrm{m}^{\circ} \mathrm{C}$ [14], in order to achieve a behavior similar to that of an air void when receiving a heat flux.

The compressive strength of the concrete was designed to be $28 \mathrm{MPa}$ (cylindrical sample at 28 days), the ratio of water to cement was 0.5 , and the sizes of fine and coarse aggregates ranged from 4.75 to $12.5 \mathrm{~mm}(60 \%)$ and from 12.5 to $25 \mathrm{~mm}$ (40\%), respectively. The thermal diffusivity of the aggregate $(\delta)$ was assumed to be $1.317 \mathrm{~cm}^{2} / \mathrm{min}$ [15]. The proportions of 


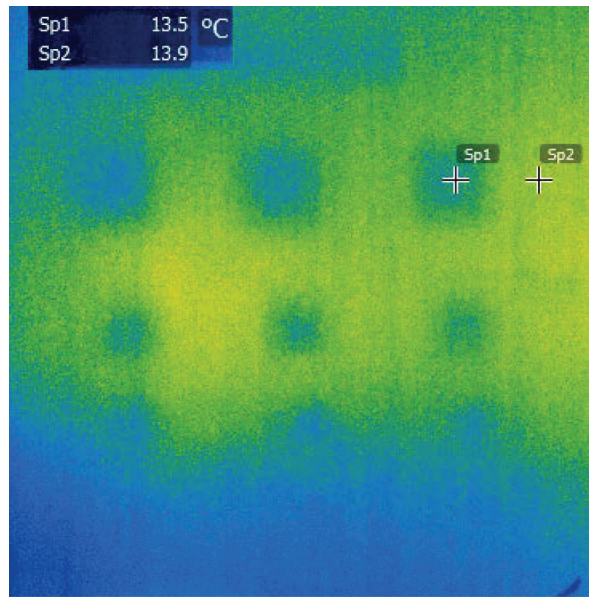

(a)

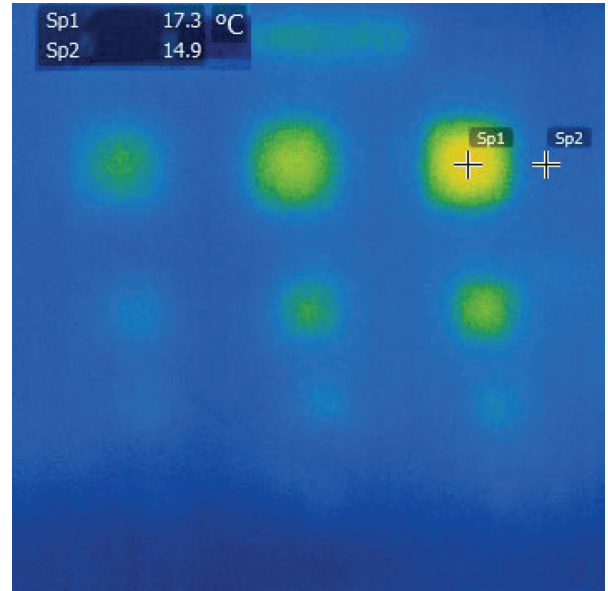

(b)

FIgURE 2: Position of the heat source (a) in the opposite face and (b) in the same face of the camera.
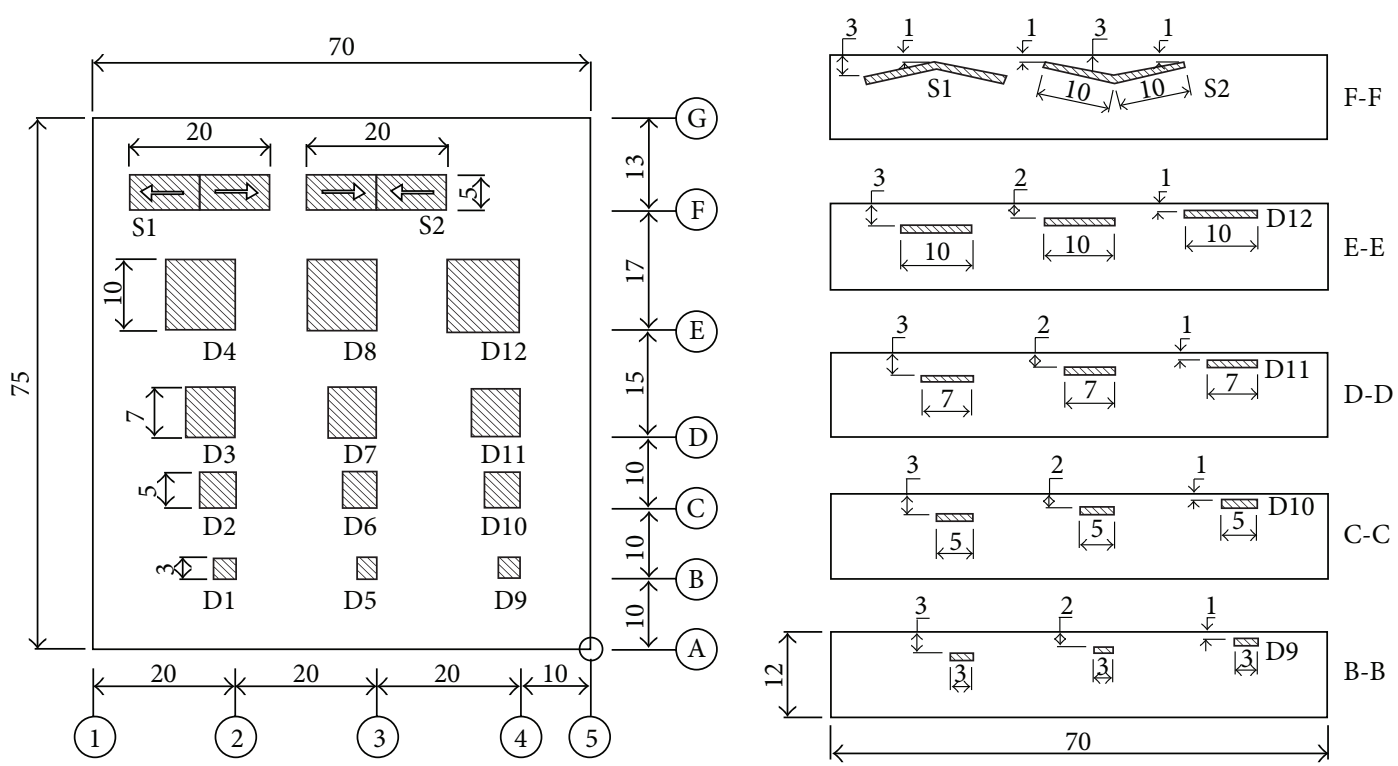

FIgURE 3: Concrete specimen.

TABLE 1: Proportions of concrete mixture.

\begin{tabular}{lccc}
\hline Cement & Sand & Aggregate & Water \\
\hline 1.0 & 1.2 & 2.6 & 0.5 \\
\hline
\end{tabular}

the mixture for the concrete specimen are listed in Table 1, and the results of the compressive strength tests on three cylindrical samples are summarized in Table 2.

3.2. Test Procedures. A careful experiment was carried out in the laboratory to minimize the influence of wind. The atmospheric temperature and relative humidity were measured using a thermohygrometer (CEM DT-615), shown in Figure 4(a). Two 500-watt halogen lamps, shown in Figure 4(b), were used as a heat source to provide heat flux
TABLE 2: Compressive strength for the cylindrical samples.

\begin{tabular}{lcc}
\hline Sample number & Compressive strength $(\mathrm{MPa})$ & Average $(\mathrm{MPa})$ \\
\hline 1 & 28.0 & \\
2 & 27.6 & 28.1 \\
3 & 28.9 & \\
\hline
\end{tabular}

to the concrete specimen. The halogen lamps were placed $0.5 \mathrm{~m}$ from the specimen and moved up and down every 15 seconds to produce a uniform heat flux over the entire surface of the specimen. After heating, an LWIR thermal camera (FLIR SC660), shown in Figure 4(c), was used to monitor and measure the variation in the temperatures of the specimen every 30 seconds during the cooling period. Some of the major technical specifications of the camera are listed in 


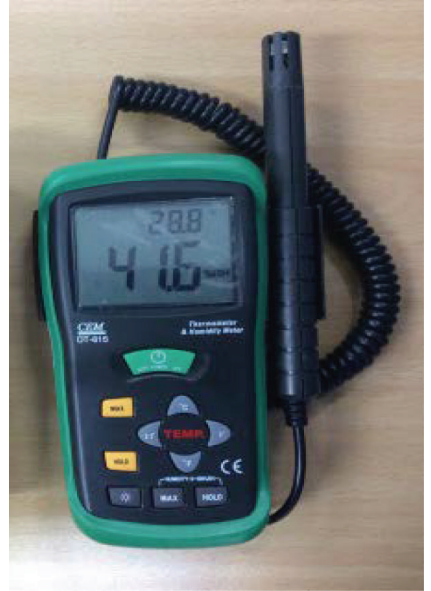

(a)

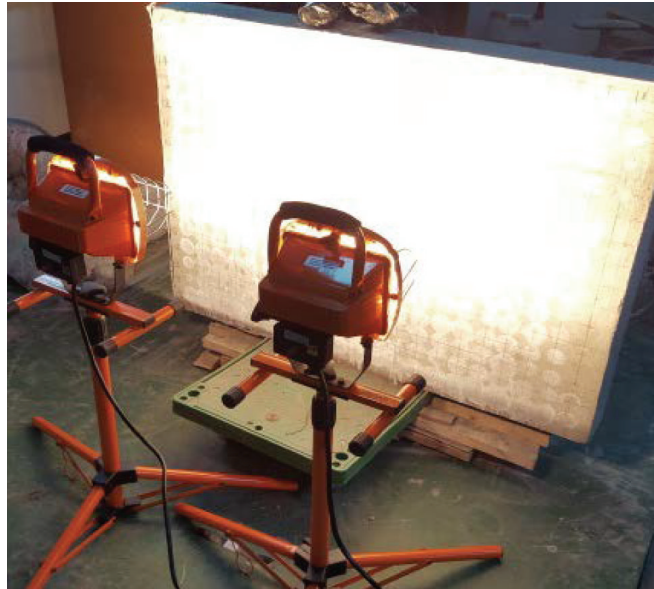

(b)

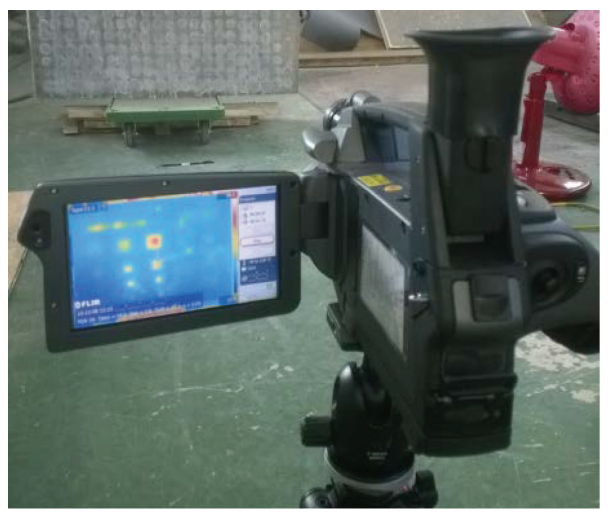

(c)

FIGURE 4: Equipment utilized in the experiment: (a) CEM DT-615, (b) Halogen lamps, and (c) IR thermal camera.

TABLE 3: Technical specifications of FLIR camera SC660 [16].

Items
IR resolution
Thermal sensitivity/NETD
Field of view (FOV)
Spatial resolution (IFOV)
Image frequency
Focal plane array (FPA)
Wavelength
Temperature range

Accuracy

Table 3. The camera automatically calculates the atmospheric transmission based on distance and relative humidity. It also provides tools to adjust the emissivity of the material and to measure temperature at any region of interest (ROI) types, such as spots, lines, and circular, rectangular, or polygonal areas. The initial parameters that were used to set up the camera are summarized in Table 4.
TABLE 4: Initial parameters of IR camera.

\begin{tabular}{lcc}
\hline Parameter & Values & Equipment or methods \\
\hline Emissivity & 0.95 & ACI $[17]$ \\
Atmospheric temperature $\left({ }^{\circ} \mathrm{C}\right)$ & 15.3 & CEM DT-615 \\
Relative humidity $(\%)$ & 30 & CEM DT-615 \\
Distance $(\mathrm{m})$ & 2.9 & Ruler
\end{tabular}

\section{Data Analysis and Quantification of Delaminations}

4.1. Analysis of Heating and Cooling Periods. The test specimen was heated by two halogen lamps for five separate heating cycles of $5,10,15,20$, and 25 minutes, and the absolute temperature contrasts of all the delaminations were measured after each heating cycle. The absolute temperature contrast at time $t, \Delta T(t)$, can be defined as the temperature difference between the surface temperature of the defective area, $T_{\text {def }}(t)$, and the temperature of the reference sound area, $T_{s}(t)$, as the following equation [7]:

$$
\Delta T(t)=T_{\text {def }}(t)-T_{s}(t) .
$$




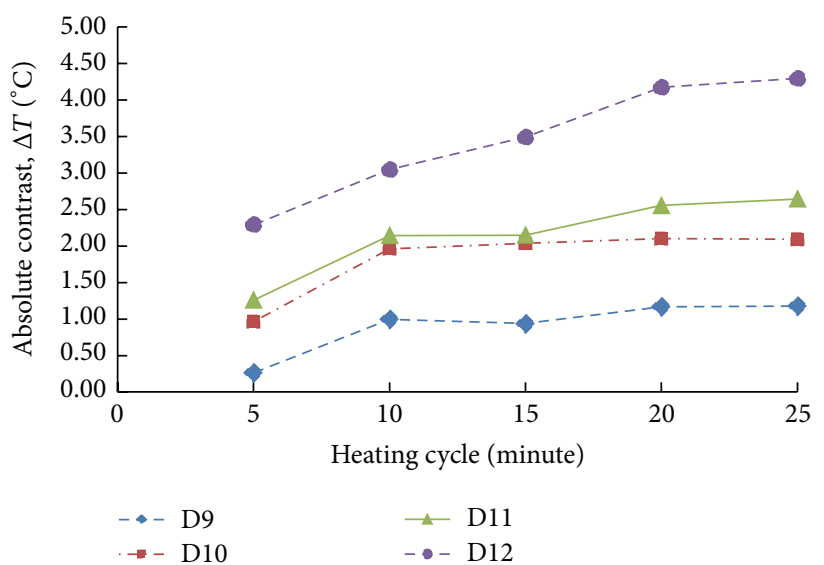

(a)

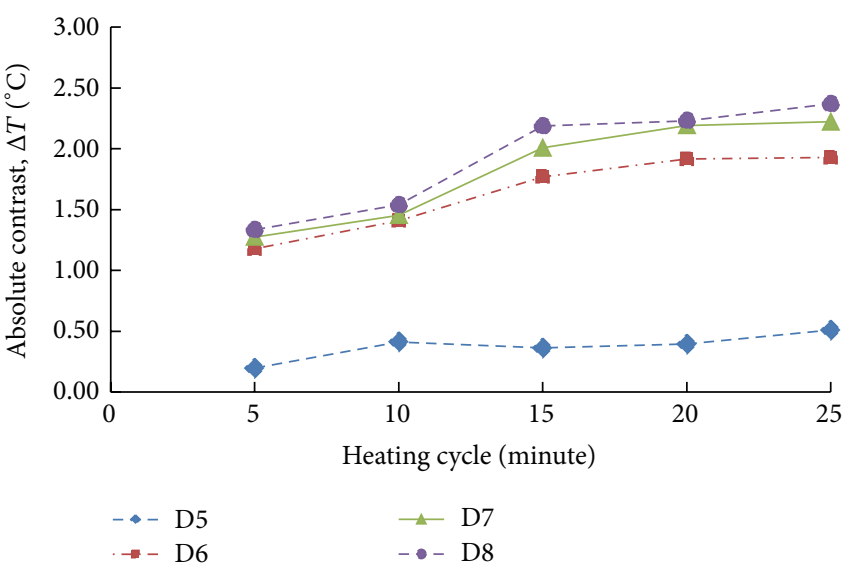

(b)

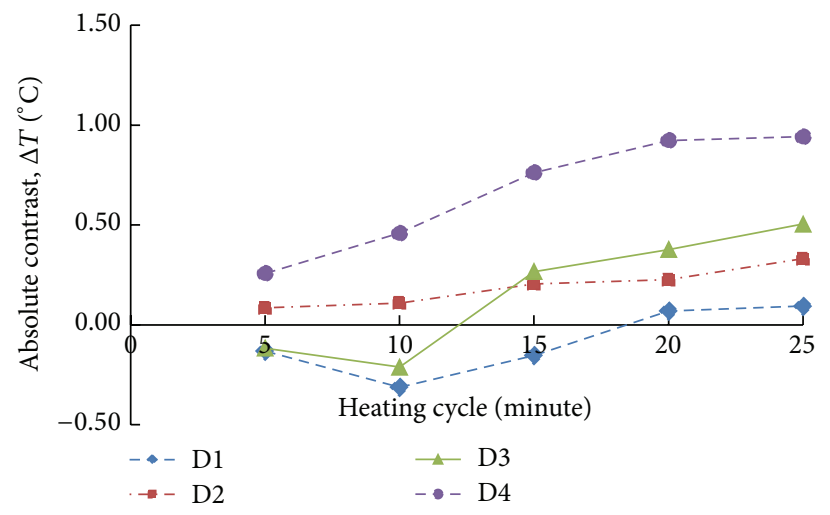

(c)

Figure 5: Absolute contrast of delaminations at (a) $1 \mathrm{~cm}$, (b) $2 \mathrm{~cm}$, and (c) $3 \mathrm{~cm}$ in depth for the five heating cycles.

Figure 5 shows the absolute temperature contrasts of the delaminations at different depths for the five heating cycles. The absolute contrast of delaminations at 1 and $2 \mathrm{~cm}$ in depth, shown in Figures 5(a) and 5(b), respectively, represents a good consistency. For delaminations at a depth of $3 \mathrm{~cm}$, the heating cycle for 10 minutes rarely showed a clear temperature contrast between the defective and surrounding sound areas, especially for the small defects. That is, delaminations D1, $\mathrm{D} 2$, and D3 are almost invisible on the thermal images at the 5- and 10-minute points of the heating cycles. In particular, delaminations D1 and D3 show negative values, as seen in Figure 5(c). Delaminations D2 and D3, whose sizes are larger than that of D1, start showing absolute temperature contrasts from the heating of 15 minutes, as shown in Figure 6(c). Since delamination prevents the heat transfer from the concrete specimen, which acts as an insulator, the absolute contrast increases with increasing heating time and decreasing defect depth. For example, at the 20-minute heating cycle, the absolute contrast of D12 (dimension of $10 \times 10 \mathrm{~cm}$ ) at $1 \mathrm{~cm}$ deep is $4.17^{\circ} \mathrm{C}$ while those of $\mathrm{D} 8$ and $\mathrm{D} 4$, with the same dimension but at 2 and $3 \mathrm{~cm}$ deep, are $2.23^{\circ} \mathrm{C}$ and $0.92^{\circ} \mathrm{C}$, respectively. Figure 7 shows the relationship between the absolute contrast and the depth of delamination of different sizes. In general, the deeper defects can be observed with a longer heating time, but a long time heating is usually impractical. As shown in Figure 7, heating of 5 minutes is enough for all delaminations at 1 and $2 \mathrm{~cm}$ deep except for the $3 \times 3 \mathrm{~cm}$ size delamination at $2 \mathrm{~cm}$ in depth, which shows approximately $0.2^{\circ} \mathrm{C}$ of the absolute temperature contrast. For delaminations at $3 \mathrm{~cm}$ in depth, the $5 \times 5 \mathrm{~cm}$ and $7 \times 7 \mathrm{~cm}$ size delaminations were detectable after 15 minutes of heating, but the $3 \times 3 \mathrm{~cm}$ size, which showed an absolute contrast lower than $0.1^{\circ} \mathrm{C}$, was not detectable in all of the heating cycles.

Monitoring of the cooling time is also important in detecting and quantifying the shape and depth of the defects in concrete structures. Figure 8 shows the cooling time of the five heating cycles for the largest delamination $(10 \times 10 \mathrm{~cm})$. For the 10 -minute heating cycle, D8 at $2 \mathrm{~cm}$ deep required around 11 minutes to reduce the absolute contrast by $0.5^{\circ} \mathrm{C}$, while D12 at $1 \mathrm{~cm}$ deep required 4.5 minutes. In addition, the delaminations that received more heating energy reached the absolute contrast more quickly than those with less heating energy did during the cooling period. That is, delamination D12 required 6 minutes to cool down $0.5^{\circ} \mathrm{C}$ of absolute contrast from the 5-minute heating, but only 2.5 minutes to cool down $0.5^{\circ} \mathrm{C}$ of absolute contrast for the 15 -minute heating, as illustrated in Figure 8.

Furthermore, Figure 9 shows the thermal IR images from the cooling period for the 20-minute heating. In general, deeper delaminations required longer cooling times than 


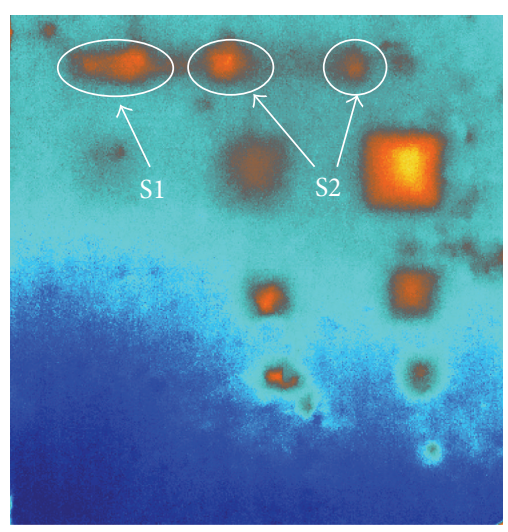

(a)

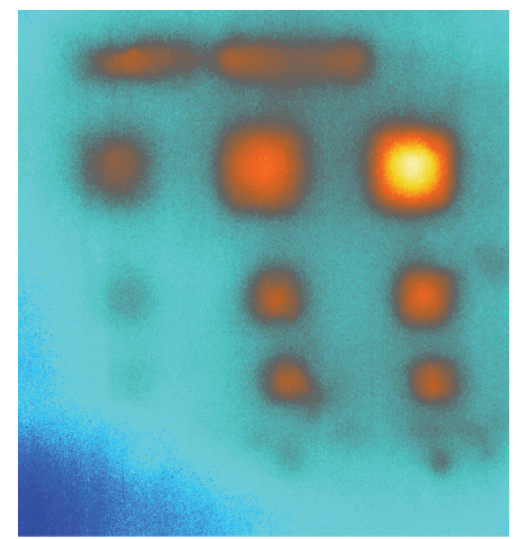

(d)

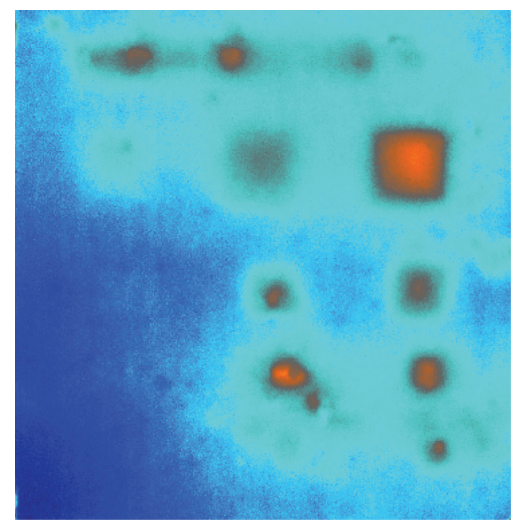

(b)

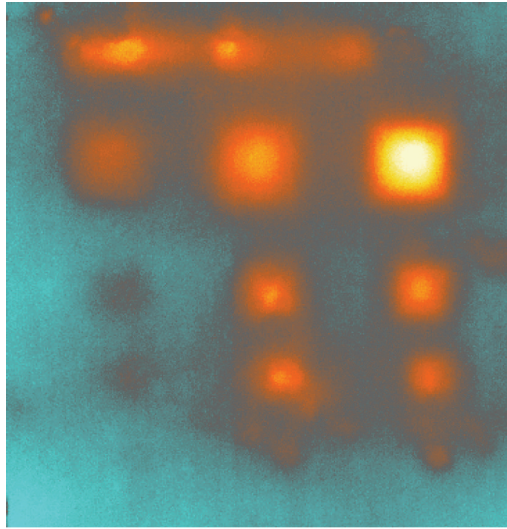

(e)

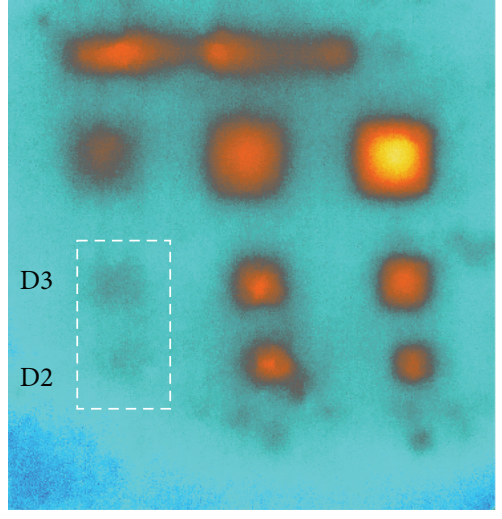

(c)

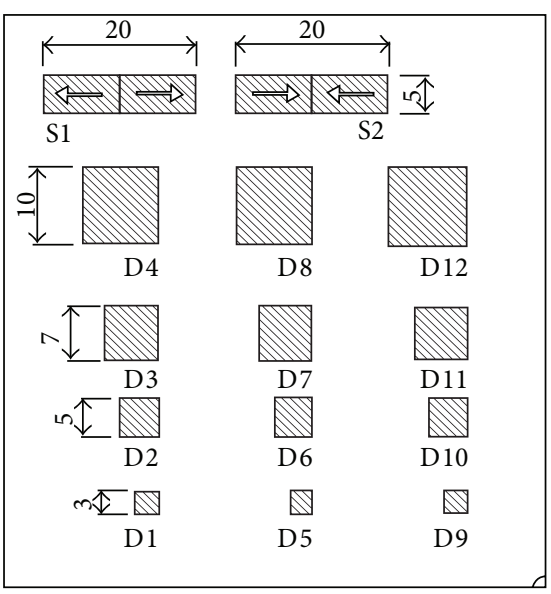

(f)

FIGURE 6: IR thermal images of the five heating cycles: (a) 5, (b) 10, (c) 15, (d) 20, and (e) 25 minutes.

shallow delaminations. As shown in Figure 9(a), immediately after the 20-minute heating, the absolute temperature contrast was apparent at all of the defects except for delaminations D1, D2, and D3 at $3 \mathrm{~cm}$ in depth. Delamination D1 was undetectable during the cooling period. However, around a cooling time of 3 minutes, D2 and D3, even though they did not satisfy the ASTM D4788 requirement of at least $0.5^{\circ} \mathrm{C}$ of absolute temperature contrast [18], gradually appeared and became continually clearer until 12 minutes of cooling under the laboratory test. After that, they became more and more unclear and finally were invisible at the 24-minute coolingdown time.

4.2. Evaluation of Defective Areas. Quantifying the percentage of delaminated or debonded area is also one of the most important factors in detecting the defective areas in concrete structures $[6,18]$. In Figure 10, the area estimated using IR thermal images is compared with the actual area of the defects in the concrete specimen at different depths for the three cycles of 15, 20, and 25 minutes of heating. With an increase in the heating time, the estimated defective areas were found to be very close to the actual areas for delaminations at $1 \mathrm{~cm}$ deep (D9 to D12) and $2 \mathrm{~cm}$ deep (D5 to D8). The estimated defective areas were smaller than the actual defective areas when applying a short time of heating, while they were larger than the actual areas for a long time of heating. In particular, the delaminations at a $3 \mathrm{~cm}$ depth showed a large difference between the estimated and actual areas after the 15-minute heating, but the difference became smaller for the 20 and 25 minutes of heating cycles. The root mean squared error (RMSE) at $3 \mathrm{~cm}$ deep indicated 16.811, 9.703, and 7.642 for 5,20 , and 25 heating minutes, respectively, as shown in Figure 10. Table 5 tabulates the estimated defective areas under the 20-minute heating cycle.

For the special shapes S1 and S2, it was difficult to recognize the shape of the defects because of the uneven heat energy absorption. The shape of the defects rarely appeared after 5-minute heating. However, the defective areas of S1 and S2 became more accurate with an increase in the heating time. The difference between the estimated and actual areas reduced from $-41 \%$ to $-18 \%$ for $\mathrm{S} 1$ and from $-39 \%$ to $-5 \%$ for S2, with an increase in the heating time from 5 to 20 minutes.

4.3. Evaluation of Defective Depth. The depth of a defect $(z)$ can be evaluated using observation time $(t)$, absolute temperature contrast $(\Delta T)$, and thermal properties of the material, including thermal diffusivity $(\delta)$, thermal conductivity $(K)$, material density $(\rho)$, and thermal capacity $(C)$. The 

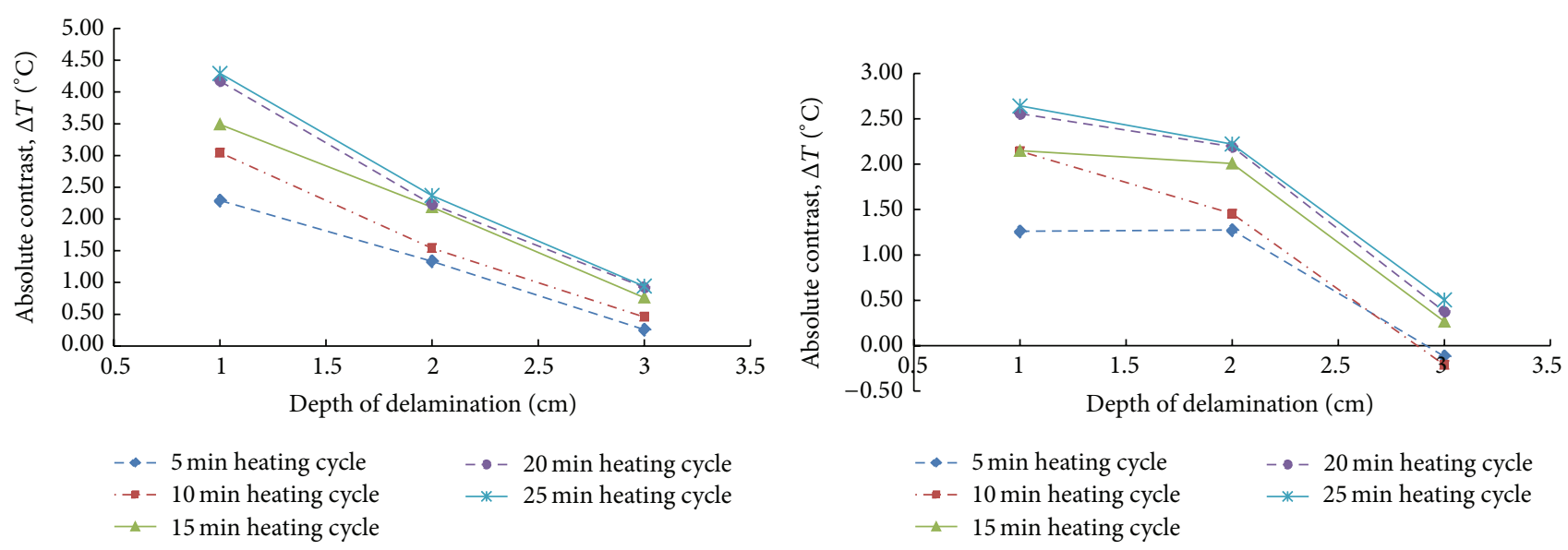

(a)

(b)

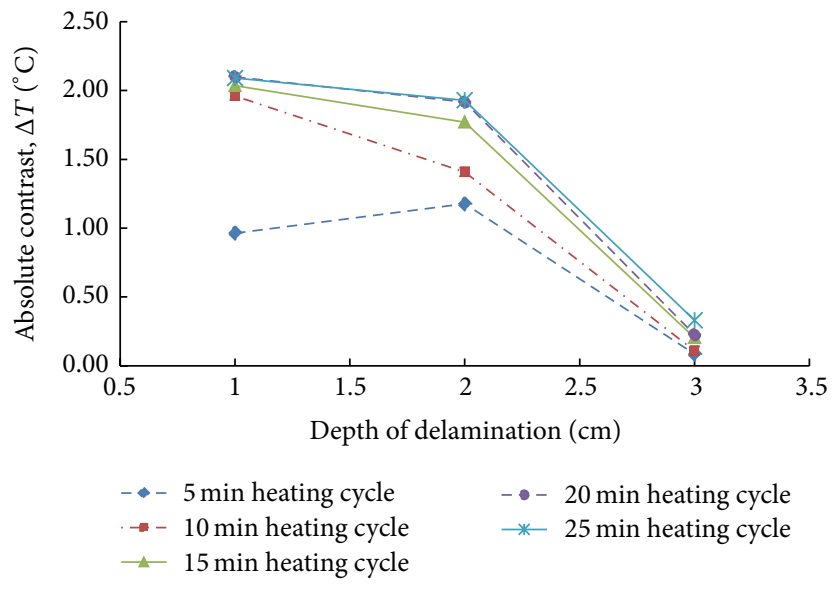

(c)

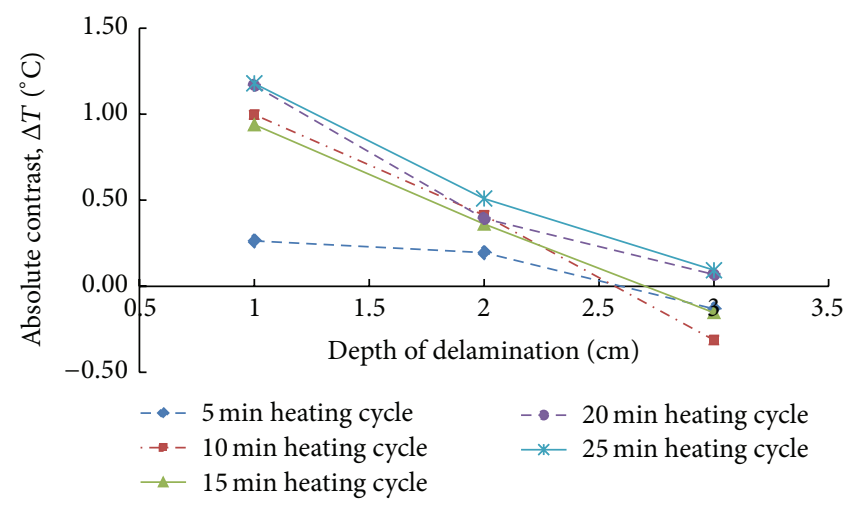

(d)

FIGURE 7: Relationship between the absolute contrast and the depth of delamination for the sizes: (a) $10 \times 10 \mathrm{~cm},(\mathrm{~b}) 7 \times 7 \mathrm{~cm},(\mathrm{c}) 5 \times 5 \mathrm{~cm}$, and (d) $3 \times 3 \mathrm{~cm}$.

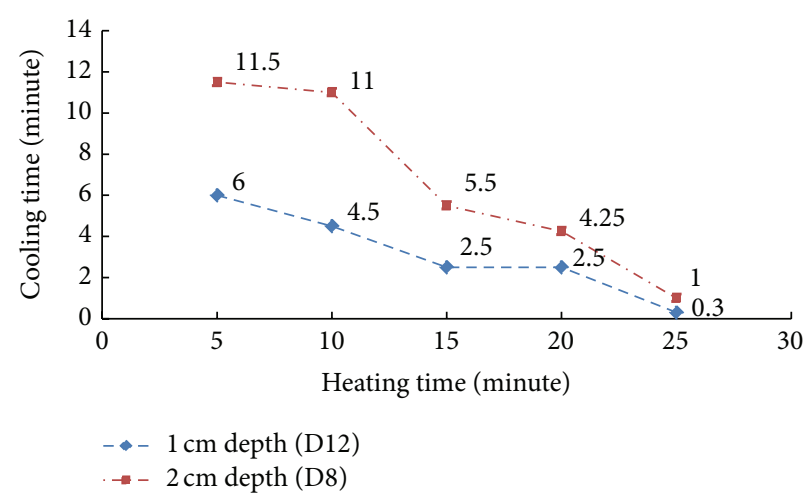

FIGURE 8: Heating and cooling time relationship for delaminations with the size of $10 \times 10 \mathrm{~cm}$ at 1 and $2 \mathrm{~cm}$ in depth.

relationship between the observation time and the depth of the defect can be expressed as [7]

$$
\begin{aligned}
& t=\frac{z^{2}}{\delta}, \\
& \delta=\frac{K}{\rho C} .
\end{aligned}
$$

The observation time is defined as the time, at which the absolute contrast remains constant or increases to the maximum contrast after the heating time [7, 8]. Figure 11 illustrates two typical shapes of cooling time. In some cases, the absolute contrast at a specific delamination temporarily increases after heating and then decreases gradually without rebounding, as shown in Figure 11(b). Then, the observation 


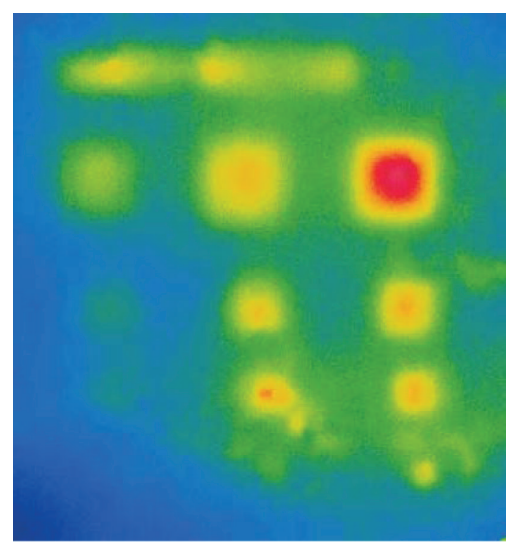

(a)

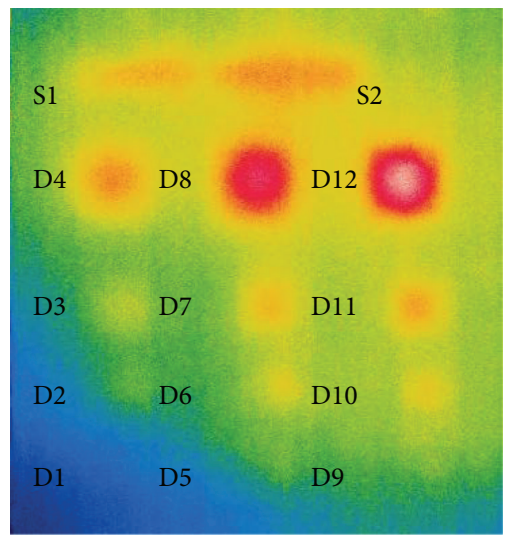

(c)

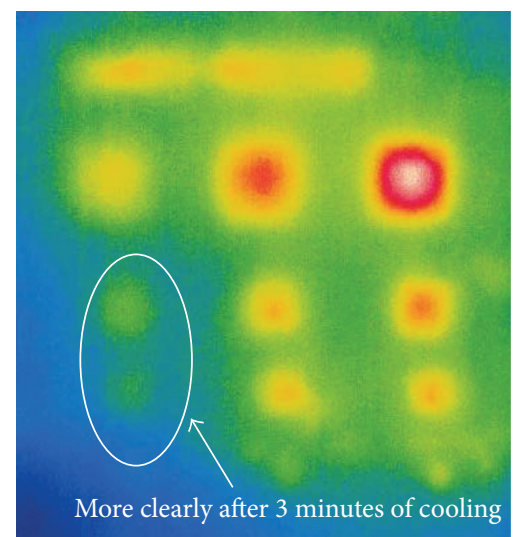

(b)

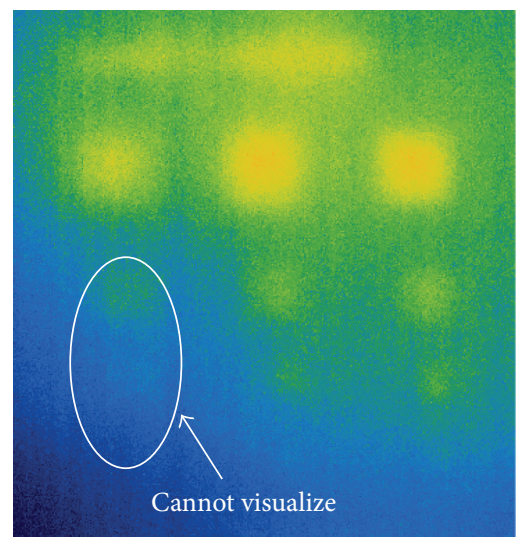

(d)

FIGURE 9: IR thermal images from the cooling period at (a) 0, (b) 3, (c) 12, and (d) 24 minutes for the 20 -minute heating cycle.

TABLE 5: Results of detecting the defective area after the 20-minute heating cycle.

\begin{tabular}{|c|c|c|c|c|c|}
\hline Defect & Dimension $(\mathrm{cm} \times \mathrm{cm})$ & Depth $(\mathrm{cm})$ & Actual area $\left(\mathrm{cm}^{2}\right)$ & Estimated area $\left(\mathrm{cm}^{2}\right)$ & Error $(\%)$ \\
\hline $\mathrm{D} 1$ & $3 \times 3$ & 3 & 9 & N/A & N/A \\
\hline $\mathrm{D} 2$ & $5 \times 5$ & 3 & 25 & 18.0 & -28 \\
\hline D3 & $7 \times 7$ & 3 & 49 & 43.9 & -10 \\
\hline $\mathrm{D} 4$ & $10 \times 10$ & 3 & 100 & 85.6 & -14 \\
\hline D5 & $3 \times 3$ & 2 & 9 & 8.0 & -12 \\
\hline D6 & $5 \times 5$ & 2 & 25 & 23.5 & -6 \\
\hline D7 & $7 \times 7$ & 2 & 49 & 45.5 & -7 \\
\hline D8 & $10 \times 10$ & 2 & 100 & 92.7 & -7 \\
\hline D9 & $3 \times 3$ & 1 & 9 & 8.8 & -2 \\
\hline D10 & $5 \times 5$ & 1 & 25 & 26.1 & 4 \\
\hline D11 & $7 \times 7$ & 1 & 49 & 51.2 & 5 \\
\hline D12 & $10 \times 10$ & 1 & 100 & 106.8 & 7 \\
\hline S1 & $5 \times 20$ & $3-1-3$ & 100 & 82.3 & -18 \\
\hline S2 & $5 \times 20$ & $1-3-1$ & 100 & 94.7 & -5 \\
\hline
\end{tabular}

Note: $(-)$ a negative sign means that the estimated area is smaller than the actual area.

$(+)$ A positive sign means that the estimated area is larger than the actual area. 


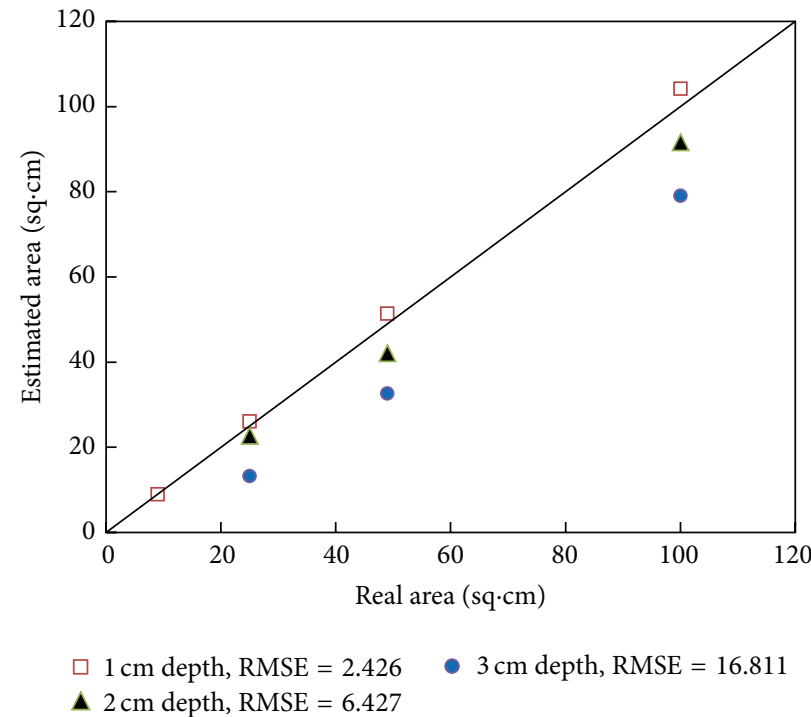

(a)

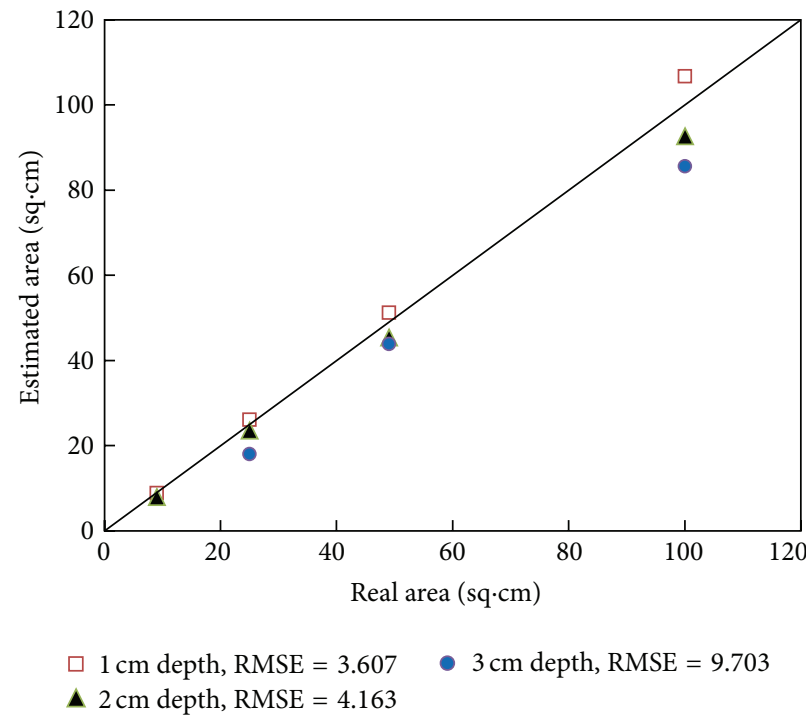

(b)

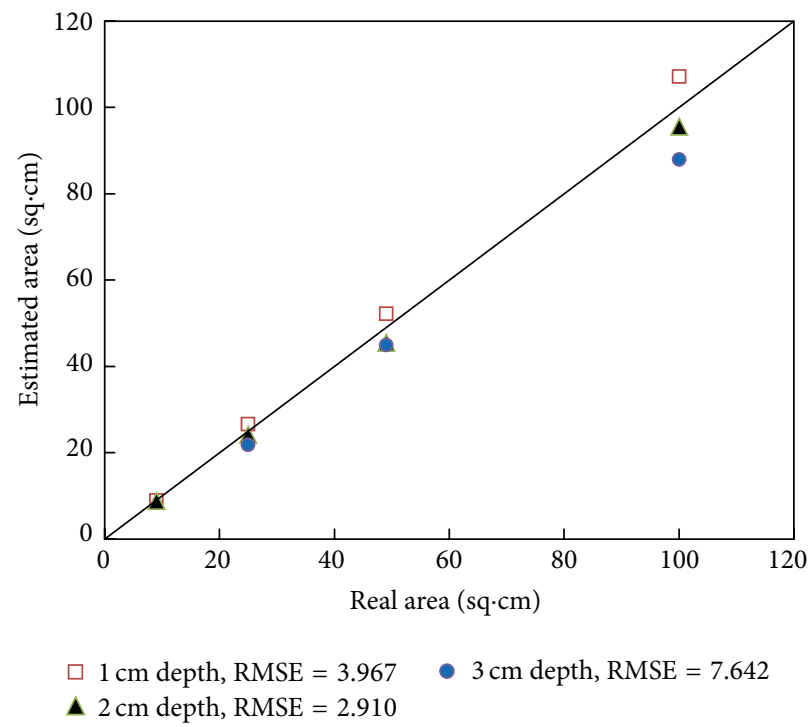

(c)

Figure 10: Comparison of the estimated and actual areas of the defects for the (a) 15-, (b) 20-, and (c) 25-minute heating cycles.

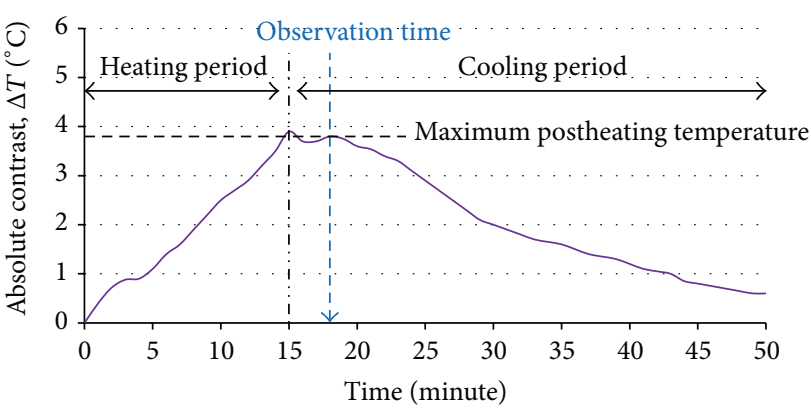

(a)

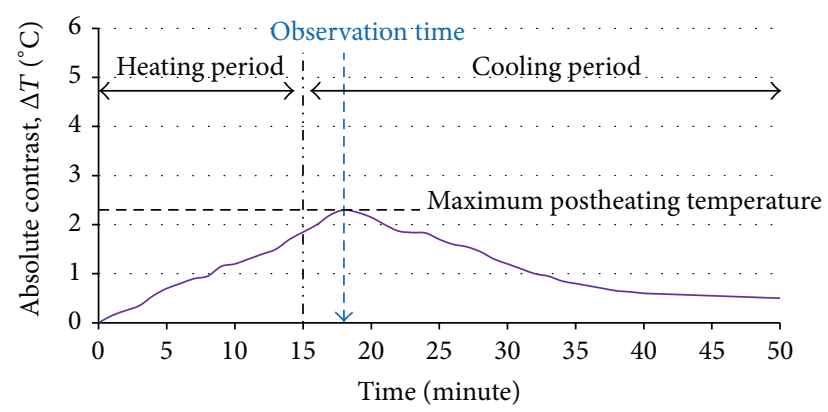

(b)

FIGURE 11: Determination of observation time for the typical shapes of variations in the absolute contrast during the cooling time. 


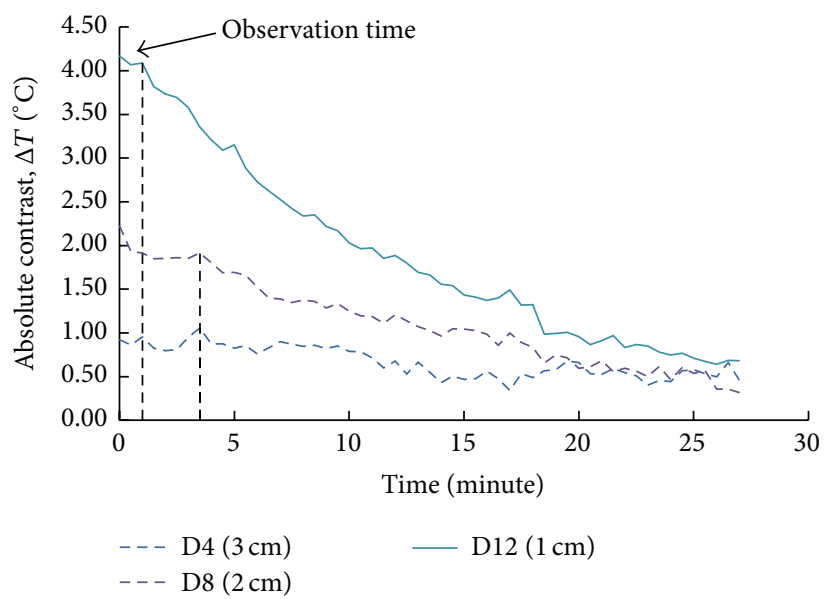

(a)

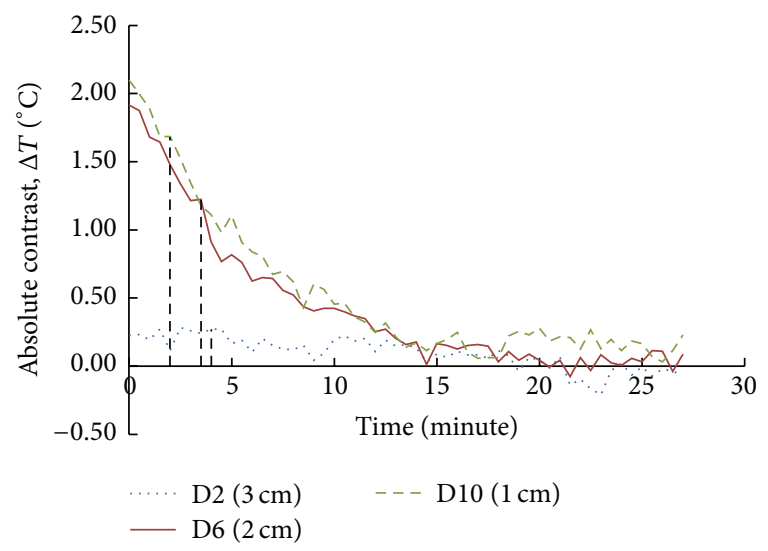

(c)

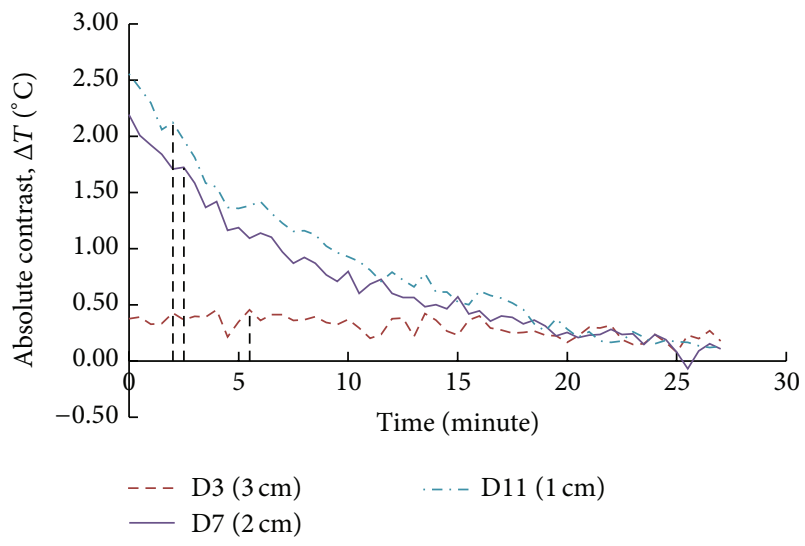

(b)

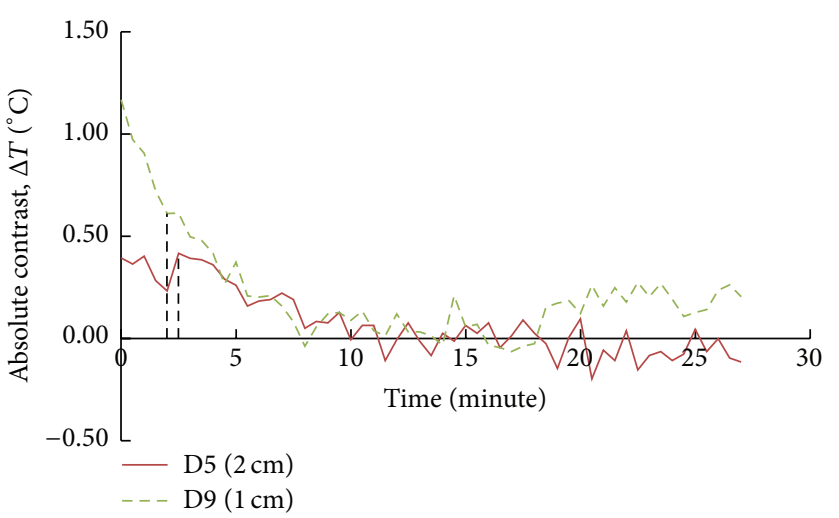

(d)

FIGURE 12: Absolute contrast during cooling time for the delaminations of sizes: (a) $10 \times 10 \mathrm{~cm}$, (b) $7 \times 7 \mathrm{~cm},(\mathrm{c}) 5 \times 5 \mathrm{~cm}$, and (d) $3 \times 3 \mathrm{~cm}$ under the 20-minute heating cycle.

time is determined to be zero when the maximum contrast appears immediately at the time of removing heat source [8].

Figure 12 shows the observation time determined for each delamination. For D12 at $1.0 \mathrm{~cm}$ in depth, the absolute contrast was $4.17^{\circ} \mathrm{C}$ immediately after removing the heat source, decreased to $4.07^{\circ} \mathrm{C}$ after 0.5 minutes, and then increased up to $4.09^{\circ} \mathrm{C}$ at 1.0 minute before continuously falling. Thus, the observation time for D12 was defined to be 1.0 minute, with an absolute contrast of $4.09^{\circ} \mathrm{C}$. The observation times for the other delaminations were also determined in the same way. The vertical dashed lines shown in Figure 12 indicate the observation times determined for each delamination. Table 6 summarizes the observation time, estimated depth, and maximum absolute contrast for the delaminations located at different depths in the specimen. According to Maldague, the radius (or width) of the defect should be at least one to two times larger than its depth to be detectable with the IR thermography technique [5]. It can be seen in Table 6 that delamination D1, with a width-to-depth ratio of 1.0, was undetected and that delaminations with a ratio less than 2.0 were difficult to identify on the IR thermal images because the absolute contrasts were too low: $0.27^{\circ} \mathrm{C}$ for $\mathrm{D} 2,0.46^{\circ} \mathrm{C}$ for $\mathrm{D} 3$, and $0.42^{\circ} \mathrm{C}$ for $\mathrm{D} 5$.

In addition, this study investigated the relationship between the observation time and the heating energy, as shown in Figure 13. The observation time tends to be constant regardless of the heating times. Figure 14 exhibits the relationship between the absolute contrast and the actual depth of the defects. The defects or delaminations were divided into four different shapes at the depths of 1,2 , and $3 \mathrm{~cm}$. As depicted in Figure 14, all the data points along each depth were well fitted with a linear relationship, and thus the correlation coefficient $\left(R^{2}\right)$ values were very close to one. For the delaminations of $5 \times 5 \mathrm{~cm}, 7 \times 7 \mathrm{~cm}$, and $10 \times 10 \mathrm{~cm}$, the values of $R^{2}$ were $0.9613,0.9179$, and 0.9425 , respectively. The absolute temperature contrast decreased with an increase in the depth of delamination; the slope also tended to decrease with an increase in the size of delamination.

\section{Conclusions}

In this study, an extensive experimental investigation was performed with respect to the size and depth of subsurface 
TABLE 6: Results of detecting the depth of the defects for the 20-minute heating cycle.

\begin{tabular}{|c|c|c|c|c|c|c|}
\hline Defect & Width-to-depth ratio & Observation time (min) & Absolute contrast $\left({ }^{\circ} \mathrm{C}\right)$ & Actual depth $(\mathrm{cm})$ & Estimated depth $(\mathrm{cm})$ & Error $(\%)$ \\
\hline D1 & 1.00 & - & - & - & - & - \\
\hline D2 & 1.67 & 4.0 & 0.27 & 3 & 2.29 & 24 \\
\hline D3 & 2.33 & 5.5 & 0.46 & 3 & 2.69 & 10 \\
\hline D4 & 3.33 & 3.5 & 1.05 & 3 & 2.15 & 28 \\
\hline D5 & 1.50 & 2.5 & 0.42 & 2 & 1.81 & 9 \\
\hline D6 & 2.50 & 3.5 & 1.22 & 2 & 2.15 & -7 \\
\hline D7 & 3.50 & 2.5 & 1.72 & 2 & 1.81 & -9 \\
\hline D8 & 5.00 & 3.5 & 1.92 & 2 & 2.15 & -7 \\
\hline D9 & 3.00 & 2.0 & 0.61 & 1 & 1.62 & -62 \\
\hline D10 & 5.00 & 2.0 & 1.68 & 1 & 1.62 & -62 \\
\hline D11 & 7.00 & 2.0 & 2.12 & 1 & 1.62 & -62 \\
\hline D12 & 10.00 & 1.0 & 4.09 & 1 & 1.15 & -15 \\
\hline
\end{tabular}

Note: width-to-depth ratio is calculated using the actual depth of the defects.

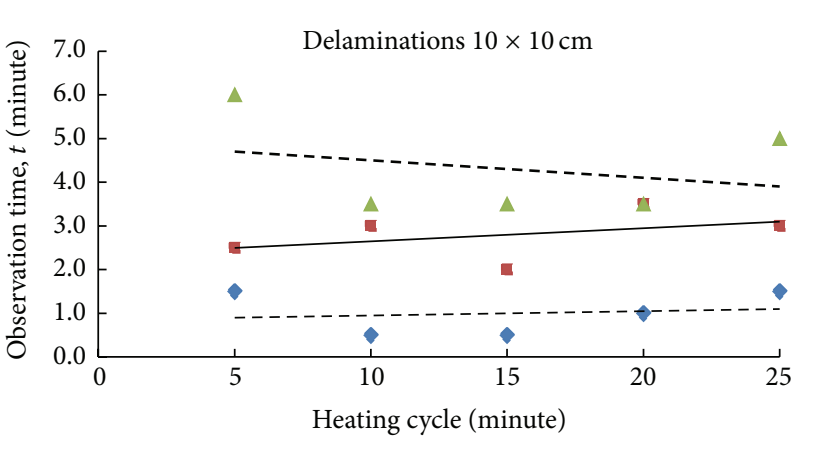

$$
\checkmark 1 \mathrm{~cm} \text { depth }
$$$$
\text { - } 2 \mathrm{~cm} \text { depth }
$$

(a)

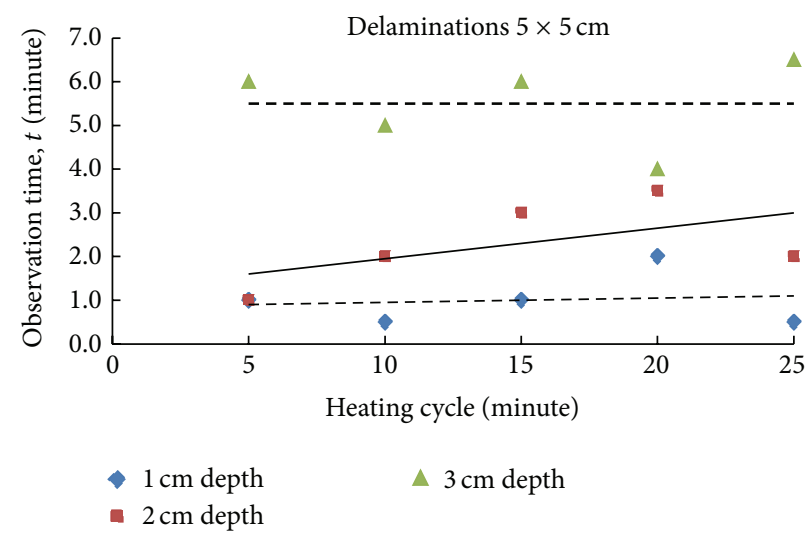

(c)

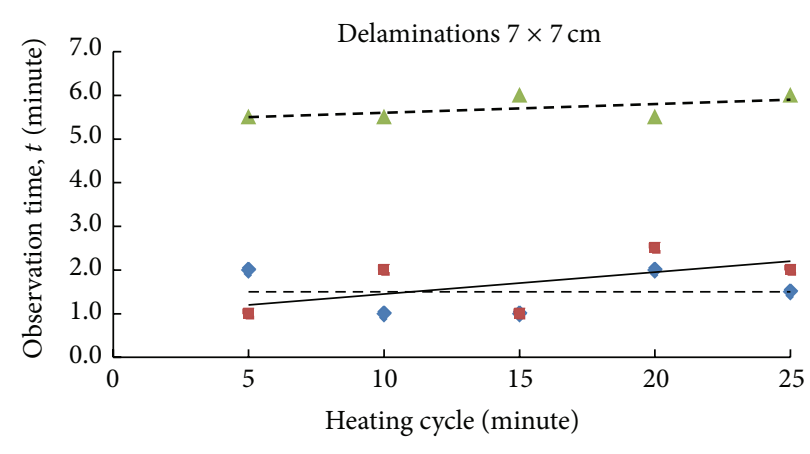

$\Delta 3 \mathrm{~cm}$ depth

(b)

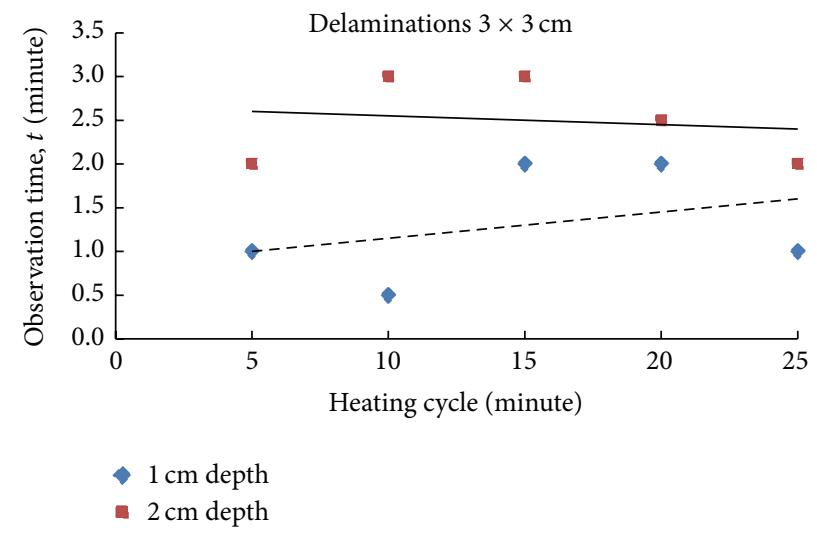

(d)

FIGURE 13: Relationship between the observation time and heating cycles for the delaminations of sizes: (a) $10 \times 10 \mathrm{~cm},(\mathrm{~b}) 7 \times 7 \mathrm{~cm},(\mathrm{c}) 5 \times$ $5 \mathrm{~cm}$, and (d) $3 \times 3 \mathrm{~cm}$.

delaminations in concrete using an LWIR thermography technique. The test focused on near-surface deteriorations (up to $3 \mathrm{~cm}$ deep) with a rectangular shape ranging in size from $3 \times 3 \mathrm{~cm}$ to $10 \times 10 \mathrm{~cm}$. According to the results of the experiment, the IR thermal technique can be effectively used to determine the size and depth of delaminations at the surface of concrete structures.

In general, more heating allows observation of deeper defects, but long heating is impractical. The results of the experiment showed that 5-minute heating was sufficient 


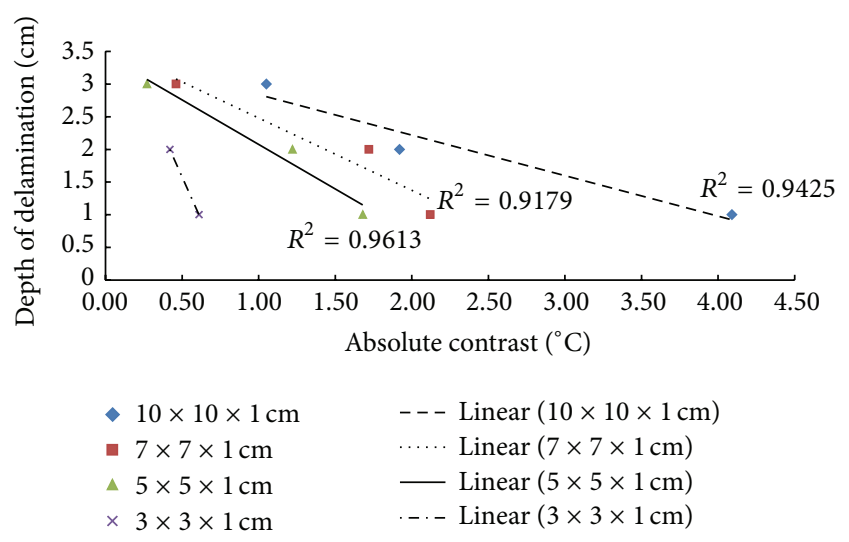

FIgURE 14: Depth versus the absolute contrast for the 20-minute heating cycle.

for delaminations at 1 and $2 \mathrm{~cm}$ in depth. Except for the smallest size of $3 \times 3 \mathrm{~cm}$, delaminations at $3 \mathrm{~cm}$ in depth were detectable when more than 15 minutes of heating were applied.

Cooling time is also important in detecting and quantifying the shape and depth of the delaminations in concrete. For 20-minute heating, the absolute temperature contrast was apparent immediately after heating for all the defects except for delaminations at $3 \mathrm{~cm}$ in depth, which gradually appeared and became clearer until a cooling time of 12 minutes has elapsed. Deeper delaminations generally required longer cooling times than shallow delaminations, and delaminations that received a relatively greater heating energy reached a target absolute contrast in a shorter period of cooling time.

The calculated defective areas were close to the actual areas for delaminations at 1 and $2 \mathrm{~cm}$ deep for a heating time of 15 minutes. For delaminations at $3 \mathrm{~cm}$ deep, there were some differences between the estimated and actual areas after 15-minute heating, but the differences decreased after 20minute heating. The size of the delaminations at $3 \mathrm{~cm}$ deep was estimated with a difference of $10 \%$ to $28 \%$ for 20 minutes of heating. In addition, delaminations with a width-to-depth ratio of 1.0 were undetected, and those with a ratio less than 2.0 were unclear.

\section{Competing Interests}

The authors declare that there are no competing interests regarding the publication of this paper.

\section{Acknowledgments}

This research was supported by Basic Science Research Program through the National Research Foundation of Korea (NRF) funded by the Ministry of Education (NRF2014R1A1A2058765) and by 2015 Jeonnam Green Environment Center (JNGEC, Korea).

\section{References}

[1] C.-C. Cheng, T.-M. Cheng, and C.-H. Chiang, "Defect detection of concrete structures using both infrared thermography and elastic waves," Automation in Construction, vol. 18, no. 1, pp. 87-92, 2008.

[2] IAEA, Guidebook on Non-Destructive Testing of Concrete Structures, IAEA in Austria, 2002.

[3] Transportation Research Board, "Nondestructive testing to identify concrete bridge deck deterioration," SHRP2 Renewal Research S2-R06A-RR-1, 2013.

[4] D. G. Pollock, K. J. Dupuis, B. Lacour, and K. R. Olsen, "Detection of voids in prestressed concrete bridges using thermal imaging and ground-penetrating radar," WSDOT Research Report, 2008.

[5] X. P. V. Maldague, Nondestructive Evaluation of Materials by Infrared Thermography, Springer, New York, NY, USA, 1993.

[6] K. Vaghefi, H. A. De Melo e Silva, D. K. Harris, and T. M. Ahlborn, "Application of thermal IR imagery for concrete bridge inspection," in Proceedings of the PCI National Bridge Conference (PCI/NBC '11), Precast/Prestressed Concrete Institute, Salt Lake City, UT, USA, 2011.

[7] T. M. Ahlborn and C. N. Brooks, Evaluation of Bridge Decks using Non-Destructive Evaluation (NDE) at Near Highway Speeds for Effective Asset Management, Michigan Technological University and Michigan Department of Transportation, Houghton, Mich, USA, 2015.

[8] K. Vaghefi, Infrared Thermography Enhancements for Concrete Bridge Evaluation, Michigan Technological University, Houghton, Mich, USA, 2013.

[9] P. Cielo, X. Maldague, A. A. Deom, and R. Lewak, “Thermographic nondestructive evaluation of industrial materials and structures," Materials Evaluation, vol. 14, pp. 452-460, 1987.

[10] R. Usamentiaga, P. Venegas, J. Guerediaga, L. Vega, J. Molleda, and F. G. Bulnes, "Infrared thermography for temperature measurement and non-destructive testing," Sensors, vol. 14, no. 7, pp. 12305-12348, 2014.

[11] M. Vollmer and K. P. Mollmann, Infrared Thermal ImagingFundamentals, Research and Applications, Viley-VCH, Weinheim, Germany, 2010.

[12] G. C. Holst, Common Sense Approach to Thermal Imaging, Spie Optical Engineering Press, Bellingham, Wash, USA, 2000.

[13] FLIR, The Ultimate Infrared Handbook for R\&D Professionals, FLIR Systems, Wilsonville, Ore, USA, 2012.

[14] K. J. Dupuis, Nondestructive Testing of Concrete Box Girder Bridges Using Thermal Imaging, Washington State University, Pullman, Wash, USA, 2008.

[15] J. F. Lamond and J. H. Pielert, Significance of Tests and Properties of Concrete and Concrete-making Materials, ASTM International, West Conshohocken, Pa, USA, 2006.

[16] FLIR SC660 Catalog, Technical Data of FLIR SC660 Infrared Camera, FLIR Systems, Wilsonville, Ore, USA, 2014.

[17] ACI, Report on Nondestructive Test Methods for Evaluation of Concrete in Structures, American Concrete Institute, Farmington, Mich, USA, 2013.

[18] ASTM, "Standard test method for detecting delaminations in bridge decks using infrared thermography," ASTM D4788-07, ASTM International, 2007. 

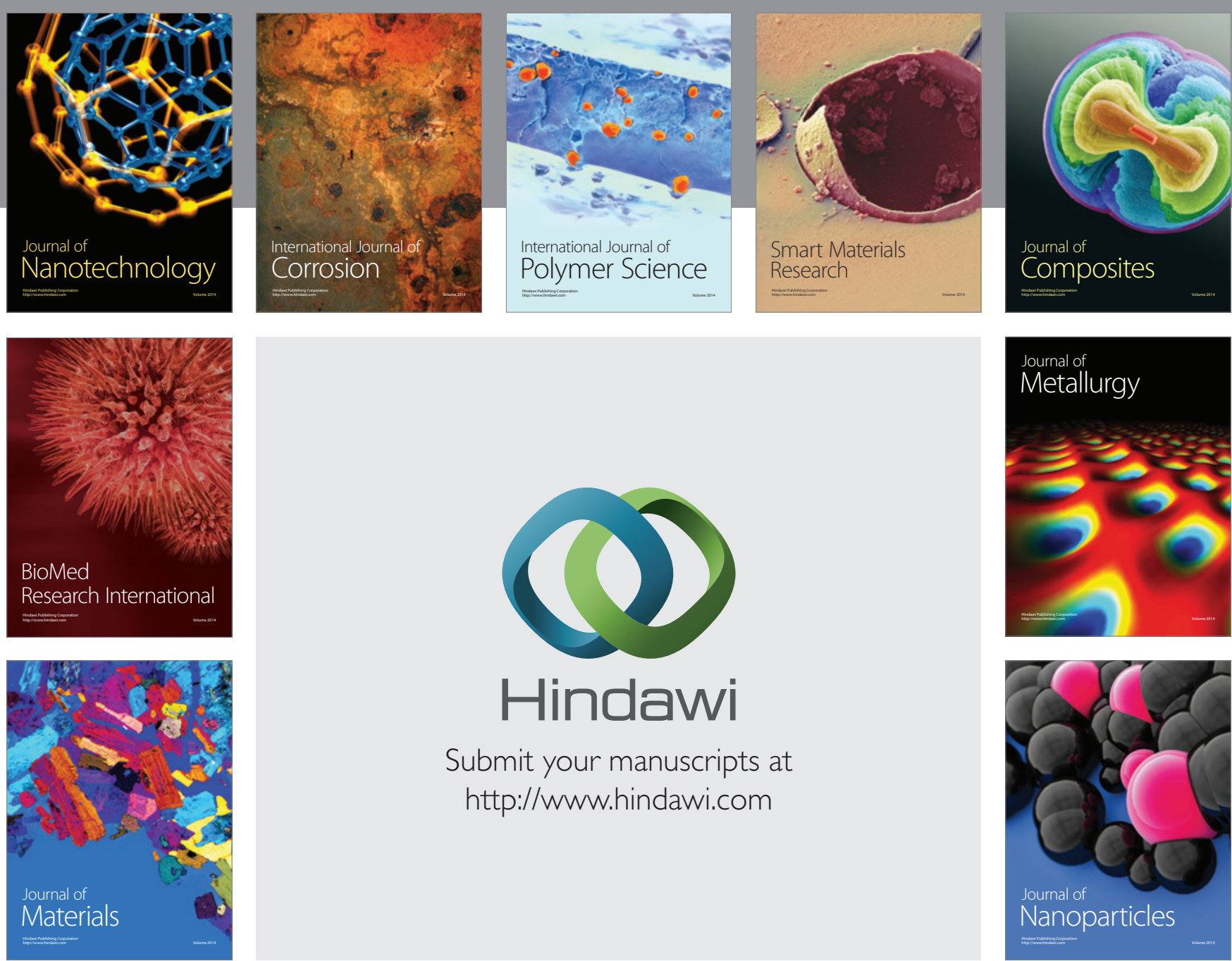

\section{Hindawi}

Submit your manuscripts at

http://www.hindawi.com

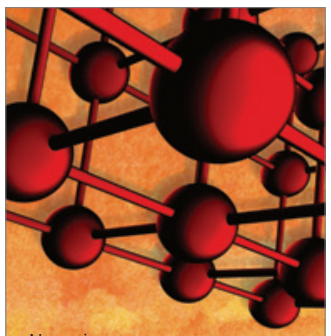

Materials Science and Engineering
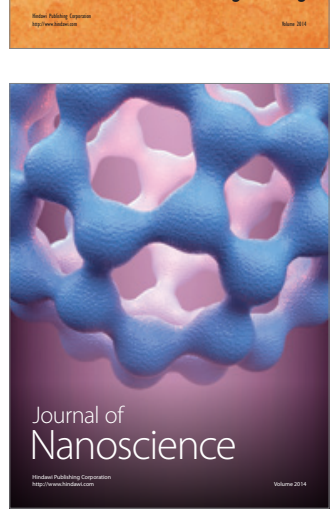
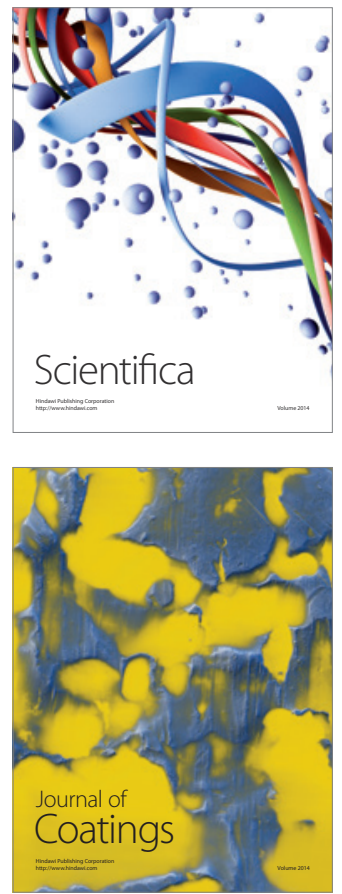
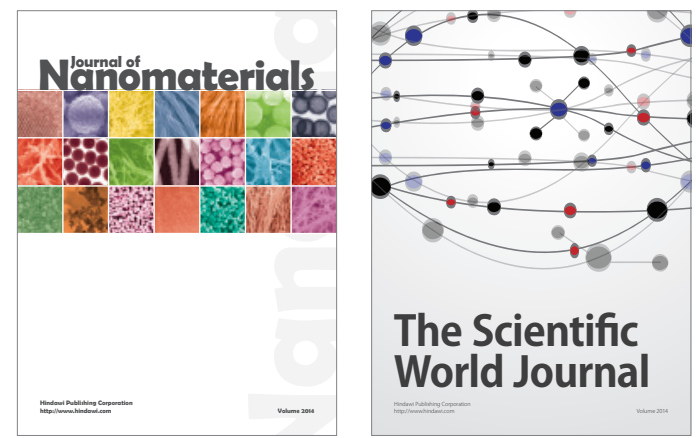

The Scientific World Journal
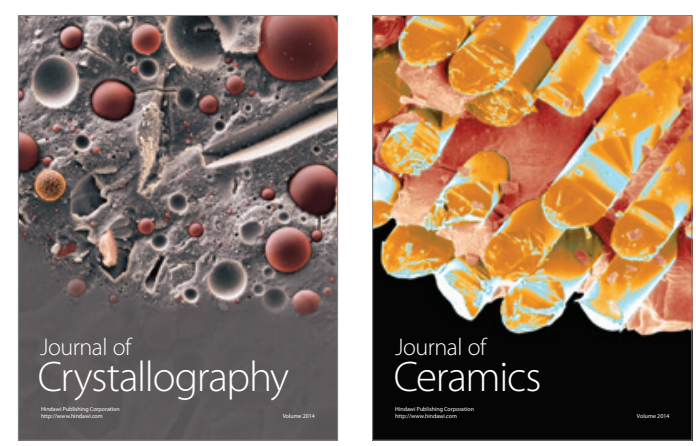
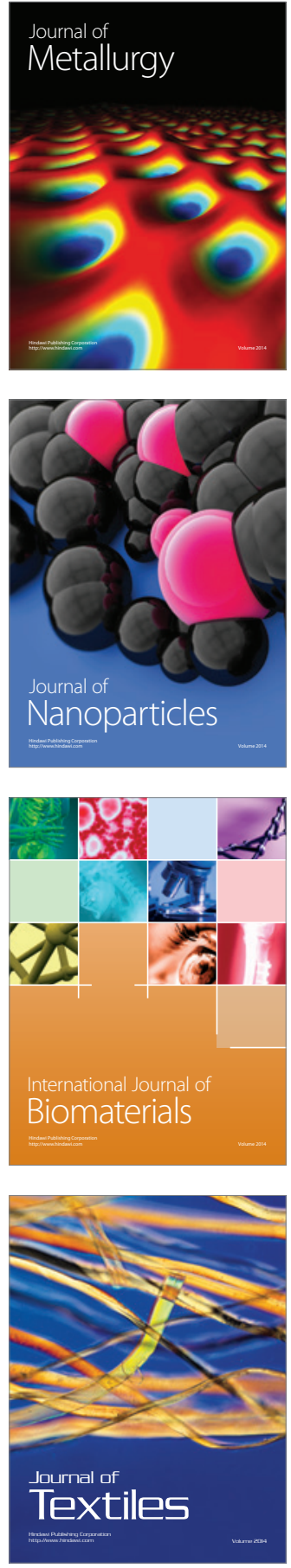